\title{
TRATAMENTO DE EFLUENTE DA INDÚSTRIA DE PROCESSAMENTO DE COCO UTILIZANDO ELETROFLOTAÇÃO
}

Frank Nelson Crespilho, Claudemir Gomes Santana e Maria Olímpia Oliveira Rezende*

Instituto de Química de São Carlos, Universidade de São Paulo, Av. Trabalhador Sãocarlense, 400, 13560-970 São Carlos - SP

Recebido em 19/5/03; aceito em 3/11/03

\begin{abstract}
BRAZILIAN INDUSTRIAL COCONUT WASTEWATER TREATMENT BY ELECTROFLOTATION. Electroflotation (EF) with aluminum electrodes was applied in the treatment of Brazilian industrial coconut wastewater. The results show that EF with polarity inversion is a very good treatment when compared to others. The removal of pollutants in the wastewater after EF with polarity inversion was $96.3 \%$ of oils and grease, $99 \%$ of color and $66 \%$ of total organic carbon. Also, metal concentrations, turbidity and total solids were reduced.
\end{abstract}

Keywords: electroflotation; wastewater treatment; industrial coconut wastewater.

\section{INTRODUÇÃO}

Os tratamentos de efluentes industriais envolvem processos necessários à remoção de impurezas geradas na fabricação de produtos de interesse. Os métodos de tratamento estão diretamente associados ao tipo de efluente gerado, ao controle operacional da indústria e às características da água utilizada ${ }^{1}$.

Dentre os vários processos, podem-se destacar os tratamentos físicos, que são caracterizados por métodos de separação de fases: sedimentação, decantação, filtração, centrifugação ou flotação dos resíduos. Esses métodos correspondem à transferência dos resíduos para uma nova fase ${ }^{2}$. Além dos métodos físicos, existem ainda processos por troca iônica ${ }^{3}$, oxidação química ${ }^{2,4}$, biológicos e adsortivos $^{2,4,5}$. Novas tecnologias também vêm sendo muito estudadas, entre elas, os processos oxidativos avançados (POA's) e as unidades de osmose reversa ${ }^{3}$.

Muitos dos processos utilizados em estações de tratamento de efluentes envolvem a adição de agentes coagulantes e floculantes, como, por exemplo, polímeros e sais de ferro e de alumínio ${ }^{6}$. Tratamentos com polímeros podem causar impactos ambientais devido à toxicidade de algumas moléculas usadas, podendo, mesmo em baixas concentrações, desequilibrar o meio ambiente em relação aos organismos aquáticos do corpo receptor ${ }^{6}$. Outras substâncias que podem causar impacto ambiental, alterando o equilíbrio do corpo receptor, são as provenientes dos coagulantes usados no tratamento químico, em que normalmente ocorre uma alteração na concentração de ânions e, conseqüentemente, uma mudança na condutividade do efluente, quando comparada com a qualidade da água de entrada na indústria ${ }^{7}$. Os coagulantes à base de sulfatos elevam a concentração desse íon no efluente final, podendo alterar a qualidade da água do corpo receptor. Excesso de sulfato no leito poderá precipitar com o cálcio presente no sedimento e na água ${ }^{8}$ ou participar de processos de oxi-redução na geração de sulfetos em condições anaeróbias 9 .

Os métodos baseados no princípio de coagulação são os mais comumente utilizados, devido a sua ampla escala de atuação e geralmente menores custos operacionais. São aplicados para remoção de

*e-mail: mrezende@iqsc.usp.br sólidos em suspensão e podem ser divididos em duas classes, quanto ao tipo de lodo gerado em coagulação com sedimentação e coagulação com flotação.

A coagulação seguida de sedimentação consiste na remoção dos sólidos presentes no efluente por meio da separação das fases sólida e liquida, sendo a fase sólida (impureza do efluente) sedimentada na parte inferior da estação de tratamento de efluente, enquanto a fase líquida (efluente tratado) é removida da estação pela parte superior, sendo descarregada no meio ambiente ${ }^{8-10}$.

Na coagulação seguida de flotação, ocorre uma inversão quanto à separação das fases, ou seja, as impurezas (fase sólida flotada) são removidas da estação pela parte superior e o efluente tratado é removido pela parte inferior. A seleção do método é realizada em função das características do efluente. Fatores operacionais como tempo de retenção, natureza do efluente, temperatura e tamanho de partículas devem ser considerados ${ }^{9}$.

No processo de flotação por ar dissolvido ocorre a suspensão do material particulado e/ou coagulado. O resíduo é carregado por microbolhas, que são injetadas no fundo de um reator. Ao chegar à superfície do reator, a suspensão (resíduo flotado) pode ser removida por processos físicos convencionais (raspagem, sucção etc.) ${ }^{9}$.

Alguns pesquisadores estão investindo em tratamentos envolvendo reatores eletroquímicos na descontaminação de efluentes contendo óleos e graxas ${ }^{10}$. Esse processo consiste na eletroflotação (EF) em que um reator eletroquímico é o centro das reações de coagulação. A EF é também chamada de eletrocoagulação e eletrofloculação.

$\mathrm{O}$ reator possui eletrodos de sacrifício de alumínio que geram íons $\mathrm{Al}^{3+}$ devido ao potencial aplicado ${ }^{10,11}$. Essa etapa faz parte do processo anódico, onde o alumínio metálico é oxidado de acordo com a Equação 1

$\mathrm{Al} \rightarrow \mathrm{Al}^{3+}+3 \mathrm{e}$

O cátion gerado na etapa anódica reage com as moléculas de água formando o agente coagulante $\left(\mathrm{Al}(\mathrm{OH})_{3}\right)$ que será o responsável pela coagulação e formação das partículas coloidais. Como se trata de uma reação de hidrólise, o $\mathrm{pH}$ ideal para formação de $\mathrm{Al}(\mathrm{OH})_{3}$ está entre 6,5 e 7,0 $0^{12}$. As Equações 2 e 3 mostram as reações de hidrólise do alumínio ${ }^{10,11}$

$\mathrm{Al}^{3+}+3 \mathrm{H}_{2} \mathrm{O} \rightarrow \mathrm{Al}(\mathrm{OH})_{3}+3 \mathrm{H}^{+}$ 
$n \mathrm{Al}(\mathrm{OH})_{3} \rightarrow \mathrm{Al}_{n}(\mathrm{OH})_{3 n}$

Além da formação do agente coagulante, a EF pode gerar microbolhas de gases que são responsáveis pela flotação de óleos, graxas e outros compostos particulados ${ }^{10,11}$. A formação desses gases está representada nas Equações 4, 5 e 6.

Evolução de hidrogênio em reações catódicas:

$2 \mathrm{H}_{2} \mathrm{O}+2 \mathrm{e}^{-} \rightarrow \mathrm{H}_{2}+2 \mathrm{OH}^{-}$

Evolução de oxigênio no processo anódico:

$$
\begin{aligned}
& 2 \mathrm{H}_{2} \mathrm{O} \rightarrow \mathrm{O}_{2}+\mathrm{H}^{+}+2 \mathrm{e}^{-} \\
& \text {ou } \\
& 2 \mathrm{OH}^{-} \rightarrow \mathrm{O}_{2}+\mathrm{H}^{+}+2 \mathrm{e}^{-}
\end{aligned}
$$

Caso o efluente contenha íons cloreto, poder-se-á formar $\mathrm{Cl}_{2}$ no ânodo, que, na presença de água, pode formar íons hipoclorito ${ }^{10}$. Esse fato pode ser considerado como uma grande vantagem da EF, uma vez os processos de geração de cloro podem ser otimizados para participar da desinfecção da água, como também eliminar odores indesejáveis. Em contraposição, deve-se ressaltar a importância do monitoramento da formação dos organoclorados, que são compostos altamente tóxicos aos seres vivos e podem ser formados nas condições citadas ${ }^{1,2}$.

Considerando que a EF gera o agente coagulante que, por sua vez, formará os flocos do material particulado e ao mesmo tempo realiza a flotação do resíduo gerado, esse processo mostra-se bastante interessante do ponto de vista de simplicidade de automação e relativo baixo custo $^{10,11}$. Além disso, nesse processo não são gerados ânions sulfato, que, por sua vez, poderiam vir a contaminar as águas dos rios?.

A EF com inversão de polaridade consiste em um sistema no qual o sentido da corrente é invertido em intervalos regulares de tempo. Assim, o cátodo torna-se ânodo e vice-versa. Esse sistema contribui para reduzir o efeito de passivação do cátodo e aumentar a vida útil do eletrodo ${ }^{11}$. Durante a eletrólise, a região próxima ao cátodo possui excesso de $\mathrm{OH}^{-}$, fazendo com que a superfície seja atacada por esses ânions ocorrendo a formação do filme passivo de acordo com as Equações 7 e 8:

$2 \mathrm{H}_{2} \mathrm{O}+2 \mathrm{e}^{-} \rightarrow \mathrm{H}_{2}+2 \mathrm{OH}^{-}$

$2 \mathrm{Al}+2 \mathrm{OH}^{-}+2 \mathrm{H}_{2} \mathrm{O} \rightarrow 2 \mathrm{AlO}_{2}^{-}+3 \mathrm{H}_{2}$

Uma vez formado o filme passivo, o processo de EF pode estar comprometido pela perda de eficiência devido ao aumento da resistividade do eletrodo ${ }^{11}$.

Porém, a literatura descreve que para reduzir o filme de óxido de alumínio é necessário que se aplique um potencial de $-1,598 \mathrm{~V}$ $(E C S)^{13}$. A reação está descrita na Equação 9

$\mathrm{Al}_{2} \mathrm{O}_{3}+6 \mathrm{H}^{+}+4 \mathrm{e}^{-} \rightarrow 2 \mathrm{Al}+3 \mathrm{H}_{2} \mathrm{O}$

Outros pesquisadores acreditam que a inversão de polaridade retarda a passivação, porém, esse tema ainda vem sendo muito discutido $^{11}$.

O efluente proveniente da indústria de processamento de coco é uma matriz muito interessante para ser aplicada em estudos de EF. Ele apresenta características bem definidas, tal como baixo $\mathrm{pH}$ devido à presença dos ácidos orgânicos existentes no $\operatorname{coco}^{14}$. O processo industrial para obtenção dos derivados do coco aumenta o risco de contaminação por óleos e graxas, fazendo-se necessário um tratamento adequado para remoção dos contaminantes. Nesse segmento industrial, podem ser gerados vários resíduos, tanto sólidos quanto líquidos. A própria unidade industrial reaproveita os resíduos sólidos como combustível para alimentar os sistemas geradores de vapor que abastecem a fábrica. Quanto aos resíduos líquidos, deles são extraídos um volume considerável de óleo após passar por uma caixa de retenção de gordura. Mesmo após esta operação, o efluente final ainda apresenta uma concentração de óleos e graxas muito elevada, necessitando ser bombeado para uma unidade de tratamento de efluente para remoção dos contaminantes.

Assim, este trabalho teve como principal objetivo desenvolver um reator eletroquímico para a EF, em escala laboratorial, tendo em vista o tratamento de uma amostra real de efluente de indústria de coco. Esse tipo de efluente foi escolhido devido à alta quantidade de agentes potencialmente contaminantes em sua composição, como óleos e graxas, fazendo dele uma boa matriz de estudo. A EF com inversão de polaridade foi utilizada e os resultados foram comparados com um sistema de EF sem inversão.

\section{PARTE EXPERIMENTAL}

\section{Construção do reator de EF}

$\mathrm{O}$ reator de EF constituiu-se por um sistema de 5 eletrodos de alumínio, sendo 3 ânodos e 2 cátodos $^{12}$. Os eletrodos foram ligados em uma fonte do tipo conversor CA/CC da marca Tecnovolt ${ }^{\circledR}$ Minitec mod. RMF 20

Bombeou-se o efluente bruto (EB) para o reator com o auxílio de uma bomba peristáltica, mantendo-se a vazão constante. Após a eletroflotação, o efluente foi bombeado para uma câmara de separação, onde o lodo formado foi separado do efluente tratado. A Figura 1 exibe as características do sistema de EF.

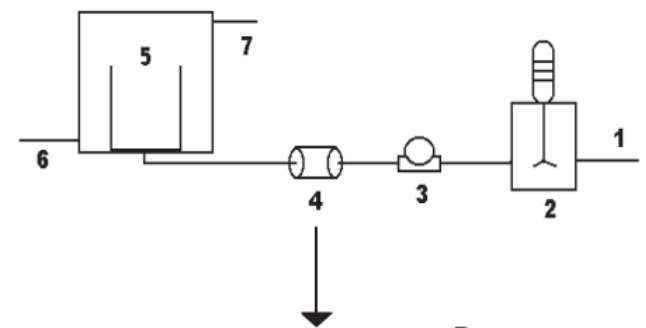

4)

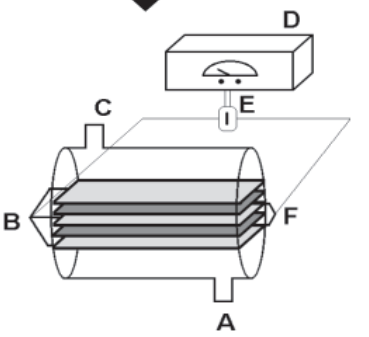

Figura 1. Sistema de EF: 1) entrada do efluente bruto; 2) câmara de homogeneização do efluente bruto; 3) bomba peristáltica; 4) reator eletroquímico; 5) câmara de separação; 6) saída do efluente tratado; 7) saída do lodo. $O$ reator de EF, que está em destaque em 4, é composto por: A) entrada do efluente bruto; B) contato elétrico do ânodo; C) saída do efluente eletroflotado; D) fonte conversora $C A / C C$; E) dispositivo para a inversão de polaridade; F) contato elétrico do cátodo

\section{Parâmetros da EF}

Alguns parâmetros foram fixados, tendo em vista resultados anteriormente obtidos em trabalhos de otimização do sistema de $\mathrm{EF}^{10-12}$. A Tabela 1 mostra os parâmetros fixados para EF. 
A condutividade do efluente bruto foi igual a $4,30 \mathrm{mS} \mathrm{cm}^{-1}$.

Tabela 1. Parâmetros fixados para a EF

\begin{tabular}{ll}
\hline Parâmetros & \\
\hline Temperatura do efluente bruto $\left({ }^{\circ} \mathrm{C}\right)$ & 25 \\
ddp aplicada (V) & 3,0 \\
Tempo total de tratamento (min) & 95 \\
Vazão de entrada $\left(\mathrm{L} \mathrm{min}\right.$ m $\left.^{-1}\right)$ & 0,032 \\
Volume de efluente tratado (L) & 3,0 \\
Tempo de retenção (min) & 0,128 \\
\hline
\end{tabular}

\section{Variação do pH do efluente bruto}

Realizaram-se quatro experimentos para avaliar o efeito do $\mathrm{pH}$ na EF. Em um deles, partiu-se do efluente in natura $\mathrm{pH}$ 4,92 (ETE1), seguido de um aumento do pH para 5,31 (ETE2) e 6,75 (ETE4), utilizando uma solução 2,0 mol L-1 de $\mathrm{NaOH}$. Tratou-se, então, o efluente nessas condições. Após verificar a qualidade do efluente tratado, realizou-se a EF com inversão de polaridade, utilizando o efluente com pH 5,35 (ETE3).

\section{EF com inversão de polaridade}

Neste experimento, a cada 2 min de eletroflotação, invertia-se a polaridade dos eletrodos por um dispositivo manual (interruptor). Fez-se, então, essa operação até completar 95 min de experimento. Em seguida, comparou-se os resultados com os sistemas sem inversão de polaridade. Para a EF com inversão de polaridade, ajustou-se o $\mathrm{pH}$ do efluente bruto para 5,35. Os demais parâmetros foram os mesmos descritos na Tabela 1 .

\section{Análise da qualidade dos efluentes tratados e do efluente bruto}

As análises dos efluentes visaram alguns parâmetros que contribuíram para a verificação da qualidade do EB e dos efluentes tratados por eletroflotação (ETEs). Realizou-se uma varredura para a identificação dos metais presentes no EB. Foram determinadas as concentrações de $\mathrm{Fe}, \mathrm{Mn}, \mathrm{Zn}, \mathrm{Cu}$ e Al. Determinaram-se, também, a turbidez, concentração de óleos e graxas, carbono orgânico total (COT), cor e sólidos totais. Todas as determinações foram realizadas em triplicata, com o cálculo do desvio da média baseado no valor do desvio padrão e utilizando a tabela $t$-Student, com $n=3$ e fator de confiança $95 \%$.

Os metais foram determinados por espectroscopia de absorção atômica (EAA) em um equipamento da marca Hitachi ${ }^{\circledR}$ Z-8100 com polarizador Zeeman. No caso do alumínio, desenvolveu-se uma metodologia de pré-concentração do metal para as matrizes cuja concentração de alumínio ficou abaixo de $5,0 \mathrm{mg} \mathrm{L}^{-1}$ (limite de quantificação de $\mathrm{Al}$ para $\mathrm{EAA}^{15}$ ). Esse método foi validado por um teste de recuperação, cujo valor foi de $98 \%$. O monitoramento do alumínio é de extrema importância pela sua toxicidade. A indústria de processamento de coco descarta seu efluente em lagos particulares. Segundo o Conselho Nacional de Meio Ambiente (CONAMA) ${ }^{16}$, não existe um limite tolerável de descarte para o alumínio nesse caso. Porém, em outros casos, os limites estabelecidos podem ser 0,1 ou 1,5 $\mathrm{mg} \mathrm{L}^{-1}$, dependendo da classe do leito receptor ${ }^{16}$.

As análises de COT foram realizadas em um analisador da marca Shimadzu ${ }^{\circledR}$ modelo TOC-VCPM (Total Organic Carbon Analizer).

As determinações de óleos e graxas e de sólidos totais seguiram os procedimentos da "American Public Health Association" $(\mathrm{APHA})^{15}$.
A redução da cor foi determinada medindo as absorbâncias das amostras na região do visível ${ }^{14} \mathrm{em}$ um espectrofotômetro da marca $\mathrm{HACH}^{\circledR}$ modelo Odyssey DR/2500. A turbidez foi determinada pelo método nefelométrico ${ }^{15}$ em um turbidímetro da marca Micronal $^{\circledR}$ modelo B250.

\section{RESULTADOS E DISCUSSÃO}

\section{Variação do pH do efluente bruto}

Na Tabela 2 apresenta-se a relação entre o pH do EB antes de ser tratado por EF e após seu tratamento.

Tabela 2. Relação entre o pH do efluente antes e depois de ser tratado por EF

\begin{tabular}{lll}
\hline Tipo de tratamento & $\mathrm{pH}_{\mathrm{i}}$ & $\mathrm{pH}_{\mathrm{f}}$ \\
\hline EF & $4,92 \pm 0,05$ & $5,66 \pm 0,05$ \\
EF & $5,31 \pm 0,05$ & $5,94 \pm 0,05$ \\
EF com inversão de polaridade & $5,35 \pm 0,05$ & $7,36 \pm 0,05$ \\
EF & $6,75 \pm 0,05$ & $9,02 \pm 0,05$ \\
\hline
\end{tabular}

$\mathrm{EF}=$ eletroflotação, $\mathrm{pH}_{\mathrm{i}}=\mathrm{pH}$ do efluente antes do tratamento; $\mathrm{pH}_{\mathrm{f}}=$ $\mathrm{pH}$ do efluente após o tratamento

Como observado, ocorre um aumento do $\mathrm{pH}$ após o tratamento do efluente. A EF tem a propriedade de aumentar o valor do $\mathrm{pH}$ do efluente, após seu tratamento, caso o efluente tenha características ácidas. Esse fato decorre do princípio de que a EF produz íons $\mathrm{OH}^{-}$, como mostrado na Equação 4. Esse efeito também foi verificado por Chen et al. ${ }^{10}$. Os autores verificaram que para um intervalo de $\mathrm{pH}$ de 6,87-9,10 obtém-se valores de $\mathrm{pH}$ no intervalo de 7,47-8,95. Também, quando o pH do efluente bruto está acima de 9,00, o pH do efluente tratado é mais baixo ${ }^{10}$. Em outras palavras, pode-se dizer que a $\mathrm{EF}$ pode neutralizar o $\mathrm{pH}$ do meio.

\section{EF com inversão de polaridade}

Como mostrado na Tabela 2, tem-se o efluente bruto com $\mathrm{pH}$ 5,35 sendo tratado por EF com inversão de polaridade e o pH aumentado para 7,35. Assim, ocorreu um aumento mais significativo no valor do $\mathrm{pH}$ quando comparado com o efluente com $\mathrm{pH} 5,31$, no qual não foi utilizada a inversão.

Quando se aplica uma ddp de 3,0 V entre os eletrodos de alumínio, criam-se, então, as condições necessárias para que ocorra a passivação dos cátodos. Esse fenômeno ocorre principalmente devido à formação de óxidos de alumínio na superfície do eletrodo ${ }^{18}$. A passivação faz com que ocorra a queda de corrente e aumente a resistividade do sistema e, conseqüentemente, o reator perde a capacidade de gerar o agente coagulante ${ }^{11-13}$. Na EF com inversão de polaridade, o eletrodo que se comporta como cátodo por um determinado tempo, passa a se comportar como ânodo após a inversão da polaridade, neste caso, a cada $2 \mathrm{~min}$. Tal inversão diminui a passivação, aumentando a vida útil do eletrodo em até três vezes, ao mesmo tempo, diminuindo a resistividade do sistema ${ }^{11}$. Assim, a corrente no reator não decai rapidamente e o eletrodo passa a liberar mais alumínio na solução e a formar maior quantidade de grupos hidroxilas, aumentando o pH e a eficiência de remoção dos poluentes.

\section{Concentração de metais}

A Tabela 3 mostra a concentração de metais nos efluentes.

É possível verificar que a EF mostrou-se eficiente em termos de 
Tabela 3. Concentração de metais nas amostras de efluentes

\begin{tabular}{|c|c|c|c|c|c|}
\hline Metal & $\mathrm{EB}$ & ETE1 & ETE2 & ETE3 & ETE4 \\
\hline Alumínio (mg L L-1) & nd & $<0,5$ & $<0,5$ & $<0,5$ & $7,1 \pm 0,9$ \\
\hline Ferro $\left(\mathrm{mg} \mathrm{L}^{-1}\right)$ & $6,00 \pm 0,05$ & $0,80 \pm 0,05$ & $0,80 \pm 0,05$ & $0,80 \pm 0,05$ & $0,73 \pm 0,06$ \\
\hline Zinco $\left(\mathrm{mg} \mathrm{L}^{-1}\right)$ & $0,31 \pm 0,05$ & nd & nd & nd & nd \\
\hline Manganês (mg L-1) & $0,47 \pm 0,05$ & nd & nd & nd & nd \\
\hline Cobre $\left(\mathrm{mg} \mathrm{L}^{-1}\right)$ & $0,10 \pm 0,05$ & nd & nd & nd & nd \\
\hline
\end{tabular}

Efluente Bruto com pH 4,92 (EB); efluente tratado por EF com pH 5,66 (ETE1); efluente tratado por EF com pH 5,94 (ETE2); efluente tratado por EF com inversão de polaridade e pH 7,36 (ETE3) e efluente tratado por EF com pH 9,02 (ETE4). nd = não detectado

remoção de metais. Pode-se observar, também, que o ETE4 apresentou a maior concentração de $\mathrm{Al}\left(7,06 \mathrm{mg} \mathrm{L}^{-1}\right)$. Isso pode ser explicado em termos do $\mathrm{pH}$ do efluente após seu tratamento $(\mathrm{pH}=9,02)$. Com o aumento do $\mathrm{pH}$, as diferentes formas de hidróxidos de alumínio, formadas durante o processo eletrolítico, tendem a ficar solúveis $^{10-12}$, devido às reações de complexação com íons $\mathrm{OH}^{-}$. Assim, uma parte do alumínio gerado e solúvel não participa das reações de coagulação e tende a ficar em solução, principalmente na forma de $\mathrm{Al}(\mathrm{OH})_{4}^{-}$. Na hidrólise do $\mathrm{Al}^{3+}$, quando o $\mathrm{pH}>7,0$, a formação dos complexos de hidróxidos de alumínio solúveis é favorecida ${ }^{12,19}$. Para ETE1, ETE2 e ETE3 o teor de alumínio residual ficou abaixo $0,5 \mathrm{mg} \mathrm{L}^{-1}$. Esse valor é semelhante ao teor de alumínio residual encontrado para amostras de efluentes tratados via coagulação com sais de alumínio, porém, pode variar dependendo do tipo de efluente ${ }^{4,5}$.

\section{Redução de cor e de turbidez}

A Figura 2 ilustra a redução de cor em função do tipo de efluente.

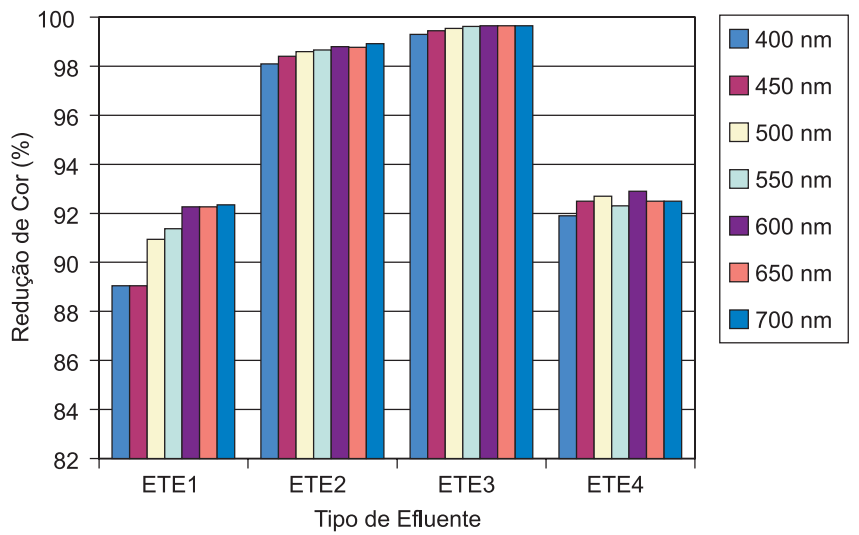

Figura 2. Redução de cor dos efluentes tratados em função do tipo de tratamento. Efluente tratado por EF com pH 5,66(ETE1); efluente tratado por EF com pH 5,94 (ETE2); efluente tratado por EF com inversão de polaridade e pH 7,36 (ETE3) e efluente tratado por EF com pH 9,02 (ETE4)

A redução de cor do efluente foi mais proeminente no ETE3, sugerindo que a técnica de inversão de polaridade é mais eficiente nesse caso. Em todos os comprimentos de onda estudados, o ETE3 apresentou uma diminuição na intensidade de cor de cerca de $99 \%$.

O EB possui característica leitosa e alta turbidez. Após o tratamento, pode-se notar que o efluente foi clarificado, apresentando também baixa turbidez.

A Figura 3 ilustra o aspecto visual dos efluentes.

A turbidez é originada pela presença de materiais insolúveis no meio aquoso, sendo assim classificado de acordo com seus tamanhos $^{19,20}$. Partículas com diâmetros inferiores a $10^{-3} \mu \mathrm{m}$, são consideradas como sólidos dissolvidos e não contribuem para o surgimento

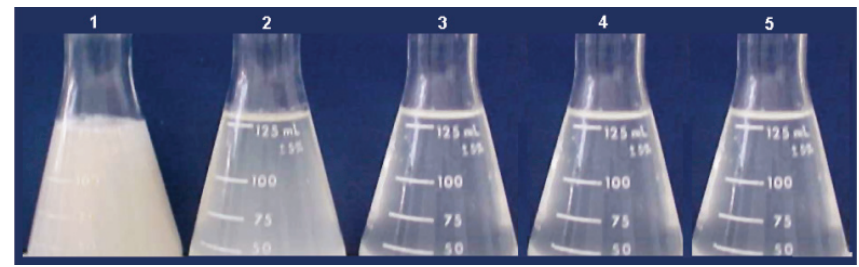

Figura 3. Fotografia em fundo escuro das amostras dos efluentes. 1) Efluente Bruto com pH 4,92 (EB); 2) efluente tratado por EF com pH 5,66 (ETE1); 3) efluente tratado por EF com pH 5,94 (ETE2); 4) efluente tratado por EF com inversão de polaridade e pH 7,36 (ETE3); 5) efluente tratado por EF com pH 9,02 (ETE4)

da turbidez. As partículas que contribuem para a turbidez são aquelas com diâmetros variando entre $10^{-3} \mu \mathrm{m}$ a $10^{-1} \mu \mathrm{m}$ (colóides) e de $10^{-1} \mu \mathrm{m}$ a $10^{3} \mu \mathrm{m}$ (sólidos suspensos) ${ }^{19,21}$. Grande parte dos microorganismos patogênicos desenvolvem-se na presença dessas partícu$\operatorname{las}^{21}$ e, por isso, a eliminação dessas partículas torna-se necessária.

A redução dos valores de turbidez estão representados na Figura 4.

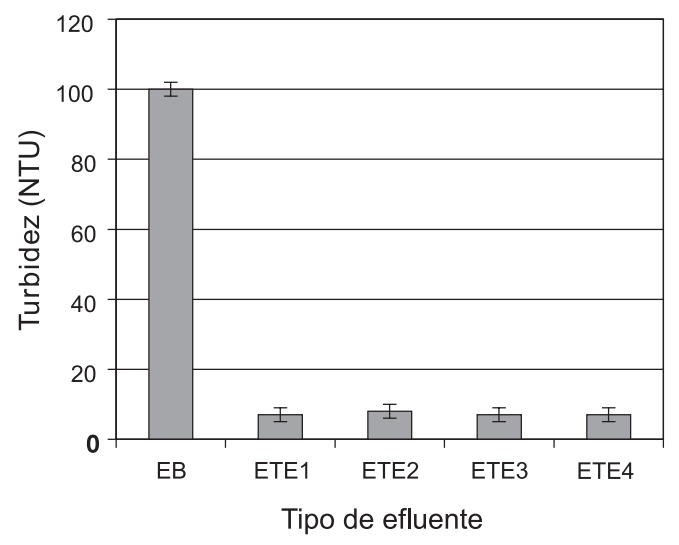

Figura 4. Valores de turbidez em função do tipo de efluente. Efluente Bruto com pH 4,92 (EB); efluente tratado por EF com pH 5,66 (ETE1); efluente tratado por EF com pH 5,94 (ETE2); efluente tratado por EF com inversão de polaridade e pH 7,36 (ETE3) e efluente tratado por EF com $p H$ 9,02 (ETE4)

Como observado, a turbidez dos ETEs ficou em torno de 7 NTU, ou seja, cerca de $93 \%$ da turbidez foi reduzida em relação ao EB.

\section{Concentração de óleos e graxa}

Uma das maiores vantagens da EF é a remoção de óleos e graxas $^{10}$. Esse fato ocorre devido à facilidade de coagulação e flotação das moléculas de óleos e graxas ${ }^{10,19}$. Como consequiência da interação 
dessas moléculas com o hidróxido de alumínio, formam-se colóides com densidade bem menor que a da água. Esses colóides deslocamse naturalmente para a superfície da câmara de separação. No entanto, com o auxílio das microbolhas geradas no processo, a flotação das partículas coloidais é mais rápida e mais eficiente. Essa peculiaridade da EF pode ser aproveitada para o tratamento de efluentes contaminados com óleos e graxas. A Figura 5 mostra a concentração de óleos e graxa nos efluentes.

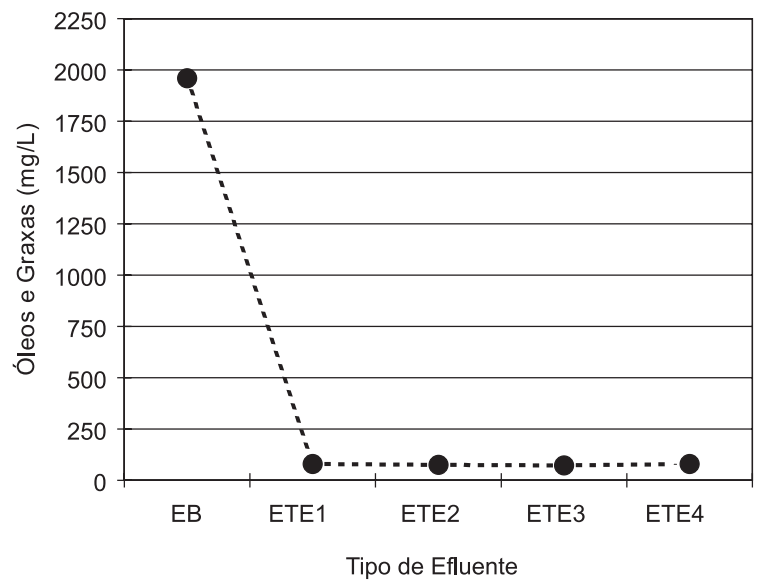

Figura 5. Valores de óleos e graxas em função do tipo de efluente. Efluente Bruto com pH 4,92 (EB); efluente tratado por EF com pH 5,66 (ETE1); efluente tratado por EF com pH 5,94 (ETE2); efluente tratado por EF com inversão de polaridade e $\mathrm{pH}$ 7,36 (ETE3) e efluente tratado por EF com $\mathrm{pH}$ 9,02 (ETE4)

O EB apresentou $1960 \mathrm{mg} \mathrm{L}^{-1}$ de óleos e graxas. Essa concentração foi reduzida para $79 \mathrm{mg} \mathrm{L}^{-1}$ (ETE1), $75 \mathrm{mg} \mathrm{L}^{-1}$ (ETE2), $73 \mathrm{mg} \mathrm{L}^{-1}$ (ETE3) e $80 \mathrm{mg} \mathrm{L}^{-1}$ (ETE4). Todos os tratamentos mostraram-se eficientes. A EF removeu 96,3\% dos óleos e graxas presentes no efluente bruto.

\section{Sólidos totais}

A determinação da concentração de sólidos totais envolve todos os compostos particulados e dissolvidos como metais, sais inorgânicos, óleos e graxas e matéria orgânica presentes no efluente ${ }^{15}$. Essa determinação é muito importante, pois, com uma metodologia simples, fornece boas informações sobre a quantidade de resíduos presentes nos efluentes. Muitas vezes, essa técnica também é chamada de resíduo de evaporação ${ }^{15}$. A Figura 6 apresenta a concentração de sólidos totais em função do tipo de efluente.

A quantidade de sólidos totais ficou em torno $3000 \mathrm{mg} \mathrm{L}^{-1}$ para todos os tipos de efluentes, sendo um pouco menor para o ETE3, que ficou em torno de $2900 \mathrm{mg} \mathrm{L}^{-1}$. Os resultados obtidos para os efluentes tratados devem-se, em grande parte, à presença de sais dissolvidos que dificilmente são removidos. Esse fato pode ser confirmado pela determinação da condutividade elétrica dos efluentes tratados que, em todos os casos, ficou em torno de $4,3 \mathrm{mS} \mathrm{cm}^{-1}$, o mesmo valor obtido para o EB (Tabela 1).

\section{Carbono orgânico total}

A matéria orgânica presente no efluente pode ser coagulada e flotada facilmente devido a sua grande afinidade pelo $\mathrm{Al}(\mathrm{OH})_{3}$ gera$\mathrm{do}^{2,20}$. A maior parte das substâncias orgânicas contém grupos carboxílicos e amina que podem conter cargas superficiais que, por sua vez, dependem do $\mathrm{pH}$ do efluente. Assim, vários tipos de reações

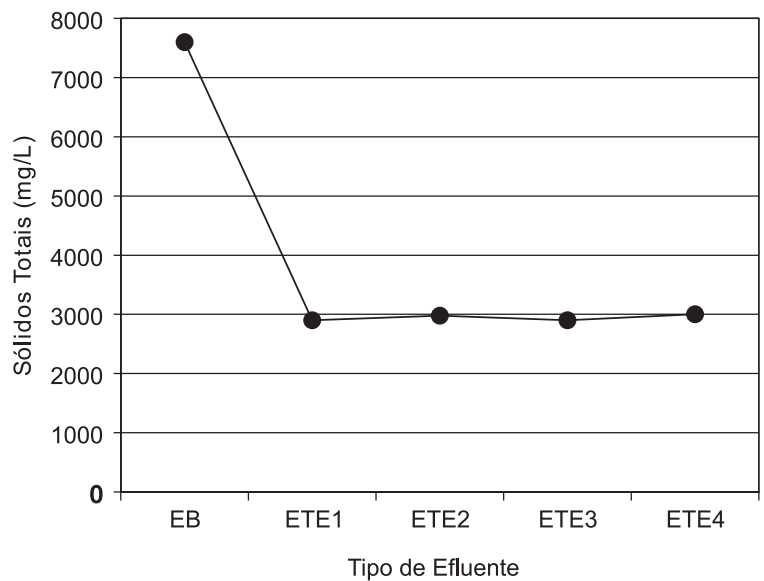

Figura 6. Sólidos totais em função do tipo de efluente. Efluente Bruto com pH 4,92 (EB); efluente tratado por EF com pH 5,66 (ETE1); efluente tratado por EF com pH 5,94 (ETE2); efluente tratado por EF com inversão de polaridade e pH 7,36 (ETE3) e efluente tratado por EF com pH 9,02 (ETE4)

químicas ocorrem entre a superfície dos colóides formados pelo hidróxido de alumínio e as substâncias orgânicas, formando colóides maiores ${ }^{2}$. Os grupamentos alifáticos presentes nas moléculas orgânicas não interagem com as moléculas de água ${ }^{20}$ e os colóides podem ser removidos facilmente por flotação. Na Figura 7 apresentam-se os resultados da redução na concentração de COT, em função do tipo de efluente.

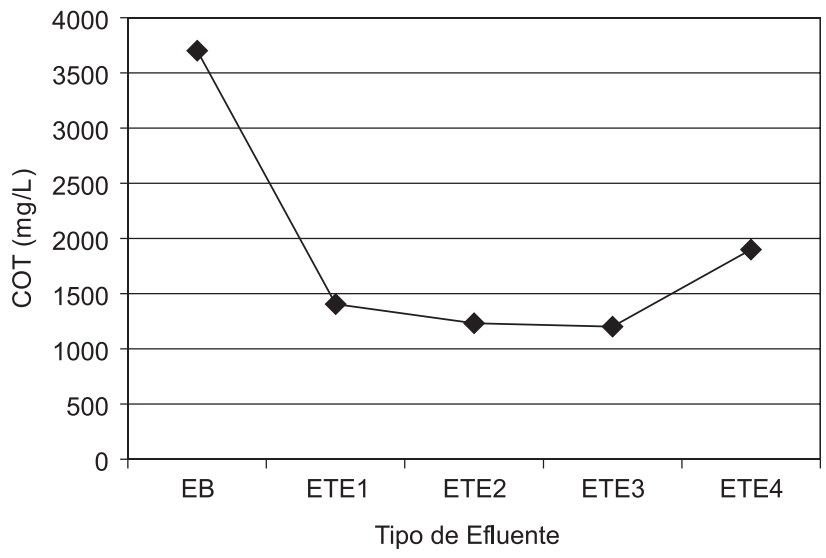

Figura 7. Carbono Orgânico Total (COT) em função do tipo de efluente. Efluente Bruto com pH 4,92 (EB); efluente tratado por EF com pH 5,66 (ETE1); efluente tratado por EF com pH 5,94 (ETE2); efluente tratado por EF com inversão de polaridade e $\mathrm{pH}$ 7,36 (ETE3) e efluente tratado por EF com pH 9,02 (ETE4)

A quantidade de COT presente na amostra de EB é muito elevada (3700 mg L $\left.\mathrm{m}^{-1}\right)$. Como se trata de um efluente proveniente da indústria de coco, a quantidade de açúcares e proteínas oriundas do leite de coco é muito alta. A EF com inversão de polaridade mostrou-se eficiente na remoção de COT, removendo cerca de $68 \%$ do carbono orgânico presente.

\section{CONCLUSÕES}

Do ponto de vista ambiental, pode-se notar que vários contaminantes tiveram suas concentrações reduzidas, mostrando que a EF é uma técnica promissora. 
A EF com inversão de polaridade fez com que o efluente assim tratado apresentasse $\mathrm{pH}=7,36$, o que pode ser considerado bom em termos ambientais. Além disso, pode-se constatar que sua eficiência na remoção dos contaminantes é maior frente à EF sem inversão de polaridade.

A EF representa uma grande alternativa frente aos tratamentos de efluentes convencionais. A viabilidade de controlar a quantidade de alumínio liberada no efluente por meio da corrente elétrica é, sem dúvida, uma grande vantagem, pois essa variável é facilmente manipulada em controle de operação em escala industrial. A não adição de sulfato ao meio também justifica o uso da técnica.

Assim, com a EF vislumbra-se uma opção vantajosa para o tratamento de efluente da indústria de coco, do ponto de vista econômico e ambiental.

\section{AGRADECIMENTOS}

Os autores agradecem à CAPES pelo financiamento do projeto.

\section{REFERÊNCIAS}

1. Freire, R. S.; Pelegrini, R.; Kubota, I. T.; Durán, N.; Peralta-Zamora, P.; Quim. Nova 2000, 23, 504.

2. Bernardo, L. D.; Métodos e Técnicas de Tratamento de Água, $I^{\mathrm{a}}$ ed., ABES: Rio de Janeiro, 1993.

3. Kunz, A.; Peralta-Zamora, P.; Moraes, S. G. de; Durán, N.; Quim. Nova 2002, 25, 78.
4. Eckenfelder, J. W. W.; Industrial Water Pollution Control, $2^{\text {th }}$ ed., McgrawHill: New York, 1989.

5. Iagrega, M. D.; Phillip, I. B.; Jeffreey, C. E.; Hazardous Waste Management, $2^{\text {th }}$ ed., Mcgraw-Hill: New York, 2001.

6. Godwin-Saad, E.; Hall, S.; Hughes, D.; Abstract of $67^{\text {th }}$ Annual Conference \& Exposition of Surface Water Quality \& Ecology, Illinois, EUA, 1994.

7. Tabatabai, M. A.; Sulfur in Agriculture, $l^{\text {th }}$ ed., Madison: New York, 1986.

8. Stumm, W.; Morgan, J. J.; Aquatic Chemistry, $1^{\text {th }}$ ed., Wiley: New York, 1981.

9. Watras, C. J.; Huckabee, J. W.; Mercury Pollution Integration and Synthesis, $I^{\text {th }}$ ed., Lewis: Boca Raton, 1994.

10. Chen, X.; Chen, C.; Yue, P. I.; Sep. Purif. Technol. 2000, 19, 65.

11. Mollah, M. Y. A.; Schennach, R.; Parga, J.; Cocke, D. I.; J. Hazard. Mater. 2001, 84, 29.

12. Crespilho, F. N.; Santana, C. G.; Rezende, M. O. O.; Saneamento Ambiental 2003, 94, 32 .

13. Kiyak, T.; Kabasakalodlu, M.; Appl. Surf. Sci. 1999, 140, 33

14. Machacon, H. T. C.; Matsumoto, Y.; Ohkawara, C.; Shiga, S.; Karasawa, T.; Nakamura, H.; JSAE 2001, 22, 349.

15. Clesceri, L. S.; Greenberg, A. E.; Eaton, A. D.; Standart Metodos for Examination of Water and Wastewater, $20^{\text {th }}$ ed., APHA: Washingiton, 1998.

16. http://www.mma.gov.br, acessada em Agosto 2003.

17. Bertazzoli, R.; Pelegrini, R.; Quim. Nova 2002, 25, 477

18. Chen, X.; Chen, G.; Yue, P. L.; Chem. Eng. Sci. 2002, 57, 2449.

19. Rubach, S.; Saur, I. F.; Filtration and Separation 1997, 34, 877.

20. Shaw, D. J.; Introdução à Química dos Colóides e de Superfícies, $1^{\text {a }}$ ed., Edgard Blucher: São Paulo, 1975.

21. Von Sperling, M.; Introdução à qualidade das água e ao tratamento de esgotos - Princípio do tratamento biológico de águas residuárias, $2^{\mathrm{a}} \mathrm{ed}$., Departamento de Engenharia Sanitária e Ambiental: Belo Horizonte,1996. 